\title{
A complication of high flow nasal cannula oxygenation therapy: Pneumothorax
}

\author{
(D) Gürkan Atay, ${ }^{1}$ (ID Seher Erdoğan, ${ }^{1}$ (D) Hüsniye İşcan, ${ }^{2}$ (D) Ceren İstanbullu² \\ ${ }^{1}$ Department of Pediatric Intensive Care, University of Health Sciences, Ümraniye Training and Research Hospital, İstanbul, Turkey \\ ${ }^{2}$ Department of Pediatrics, University of Health Sciences, Ümraniye Training and Research Hospital, İstanbul, Turkey
}

\begin{abstract}
High flow nasal cannula oxygenation (HFNC) therapy is a safe and comfortable treat-ment method that has been widely used in both pediatric and adult patients in recent years. A two-month-old male patient admitted to our emergency department was hospita-lized with a pre-diagnosis of acute bronchiolitis, and HFNC treatment was started due to respiratory distress. Pneumothorax was observed in the chest radiography of the patient who developed tachypnea and dyspnea during follow-up. Underwater drainage was per-formed by inserting a thorax catheter. The thoracic catheter was removed due to clinical and radiological improvement on the fifth day of the treatment. With this case report; We wanted to emphasize that although it is a rare complication during HFNC treatment, pneumothorax may develop and the patient should be followed closely.
\end{abstract}

Keywords: Child; pneumothorax; intensive care unit; high flow nasal cannula.

Cite this article as: Erdoğan S, Atay $\mathrm{G}$, İşcan $\mathrm{H}$, İstanbullu C. A complication of high flow nasal cannula oxygenation therapy: Pneumothorax. Jour Umraniye Pediatr 2021;1(1):24-27.

ORCID ID

S.E.: 0000-0002-3393-3363; G.A.: 0000-0002-0317-5872; H.I.: 0000-0001-9474-2715; C.I.: 0000-0002-2250-9241

${ }^{1}$ Sağlık Bilimleri Üniversitesi Ümraniye Eğitim ve Araştırma Hastanesi, Çocuk Yoğun Bakım Kliniği, İstanbul, Türkiye

${ }^{2}$ Sağlık Bilimleri Üniversitesi Ümraniye Eğitim ve Araştırma Hastanesi, Çocuk Sağlığı ve Hastalıkları Anabilim Dalı, İstanbul, Türkiye

Received (Başvuru tarihi): 27.10.2020 Accepted (Kabul tarihi): 24.11.2020 Online (Online yayınlanma tarihi): 15.01.2021

Correspondence (iletişim): Dr. Seher Erdoğan. Sağlık Bilimleri Üniversitesi, Ümraniye Eğitim ve Araştrma Hastanesi,

Çocuk Sağlığı ve Hastalıkları Anabilim Dalı, İstanbul, Türkiye.

Phone (Tel): +90 5326678370 e-mail (e-posta): seher70@gmail.com

(c) Copyright 2021 by Istanbul Provincial Directorate of Health - Available online at www.umraniyepediatri.com 


\title{
Yüksek akımlı nazal kanül oksijenasyon tedavisinin bir komplikasyonu: Pnömotoraks
}

\begin{abstract}
ÖZET
Yüksek akımlı nazal kanül oksijenasyon (YANKO) tedavisi, son yıllarda gerek pediatrik gerekse erişkin hastalarda yaygın olarak kullanılan güvenli ve konforlu bir tedavi yöntemidir. Acil servisimize başvuran iki aylık erkek hasta akut bronşiyolit ön tanısı ile servise yatrılmış, solunum sıkıntısı olması nedeniyle YANKO tedavisi başlanmıştı. İzle-minde takipne ve dispne gelişen hastanın akciğer grafisinde pnömotoraks oluştuğu gö-rülmüştür. Toraks kateteri takılarak sualtı drenajı uygulanmıştı. Tedavinin beşinci günün-de klinik ve radyolojik düzelme olması üzerine toraks kateteri çekilmiştir. Bu olgu ile; YANKO tedavisi sırasında nadir bir komplikasyon olmakla birlikte pnömotoraksın gelişe-bileceği ve hastanın yakın takip edilmesi gerektiği vurgulanmak istenmiştir.
\end{abstract}

Anahtar Kelimeler: Çocuk; pnömotoraks; yoğun bakım ünitesi; yüksek akımlı nazal kanül.

\section{Giriş}

Yüksek akımlı nazal kanül oksijenasyon (YANKO) tedavisi, son yıllarda gerek pediatrik gerekse erişkin hastalarda yaygın olarak kullanılan güvenli ve konforlu bir tedavi yöntemidir.

Solunum yolu hastalıklarında oksijenasyonu ve ventilasyonu düzeltmeye yönelik YANKO sistemi ile; nemlendirilmiş oksijen uygulaması, oksijen konsantrasyonunun \%100'e kadar arttırılabilmesi, nemlendirilmiş oksijenin sıcaklığının $34-37^{\circ} \mathrm{C}$ arasında ayarlanabilmesi, yüksek oksijen içerikli ılık nemli havanın etkisiyle mukosiliyer klerensin arttırılması ve sekresyonların atılımının kolaylaştırılması sağlanabilmektedir. Yüksek akım etkisiyle nazofarengeal ölü boşluğun yıkanması sayesinde alveol içi oksijen ve karbondioksit miktarı arttırılarak daha etkili oksijenasyon ve gaz değişimi gerçekleşebilir. Böylece solunum işinin ve inspiratuvar direncin azaltılması, hava yollarının genişlemesi, ısıtılmadan uygulanan soğuk oksijenin yaratacağı inflamasyonun önüne geçilerek hava yolundaki iletim ve kompliyansın arttırılması, mukus oluşumunun ve atelektazinin giderilmesi mümkün olmaktadır (1). Akut bronşiyolit, bronkopnömoni, astım, interstisyel akciğer hastalıkları ve diğer süreğen akciğer hastalıklarının akut alevlenmeleri, konjestif kalp yetersizliği, obstrüktif uyku apnesi, ekstübasyon aşaması gibi geniş kullanım endikasyonları bulunan bu tedavi yönteminin giderek artan sıklıkta kullanıldığı görülmektedir $(2,3)$.

Akut bronşiyolit tanısı ile yatırılan ve YANKO tedavisi izlemi sırasında pnömotoraks gelişen iki aylık bu olgu ile, nadir de olsa tedavi sırasında gelişebilecek komplikasyonlara dikkat çekmek istenmiştir.

\section{OLGU SUNUMU}

Öksürük ve hırıltılı solunum yakınmaları olan ve bir sağlık kuruluşuna başvuran iki aylık erkek hastanın, üst solunum yolu infeksiyonu tanısı ile tedavisinin düzenlendiği ve yakınmalarının devam etmesi üzerine acil servisimize başvurduğu öğrenilmiştir. Hastanın fizik muayenesinde; genel durumu orta, bilinci açık ve huzursuz olduğu görülmüştür. Kalp tepe atımı 142/dakika, solunum sayısı $57 /$ dakika, ateşi $36.9^{\circ} \mathrm{C}$ olarak tespit edilmiştir.
Orofarenks muayenesi doğal bulunan hastanın dinlemekle solunum sesleri kaba idi, ekspiryum uzundu ve ronküs mevcuttu. Subkostal ve interkostal retraksiyonları vardı. Hastanın diğer sistem muayene bulguları normal saptanmıştır. Damar yolu açılmış, intravenöz sıvı uygulanmış ve peroral beslenmesi kesilmiştir. Hastaya ampisilin, sefotaksim, azitromisin ve oseltamivir tedavileri başlanmıştır.

Arteriyel kan gazında; $\mathrm{pH}: 7.38, \mathrm{PaCO}_{2}: 45.7 \mathrm{mmHg}, \mathrm{PaO}_{2}: 78$ $\mathrm{mmHg}, \mathrm{SaO}_{2}: \% 98, \mathrm{HCO}_{3}: 26.3 \mathrm{mmol} / \mathrm{L}, \mathrm{C}$-reaktif protein: 0.2 $\mathrm{mg} / \mathrm{dL}$, tam kan sayımında beyaz küre: $7.86 \times 10^{3} / \mathrm{uL}$, hemoglobin: $10.8 \mathrm{~g} / \mathrm{dL}$, hematokrit: \%31.5, trombosit sayısı: 563 $\mathrm{x} 10^{3} / \mathrm{uL}$ idi. Serum elektrolit ve biyokimya düzeyleri normal olan hastanın kan kültüründe üreme olmamıştır. Akciğer grafisinde; sağ akciğer üst lobda belirgin infiltrasyon görülmüştür (Şekil 1).

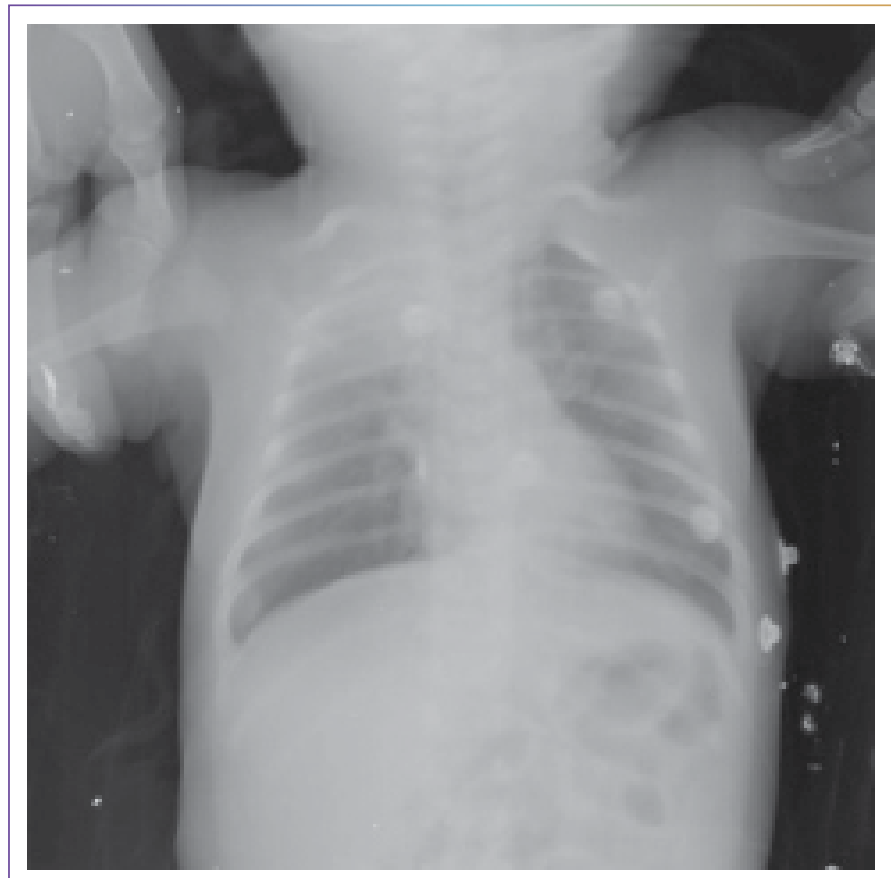

Şekil 1. Sağ akciğer üst lobda infiltrasyon. 


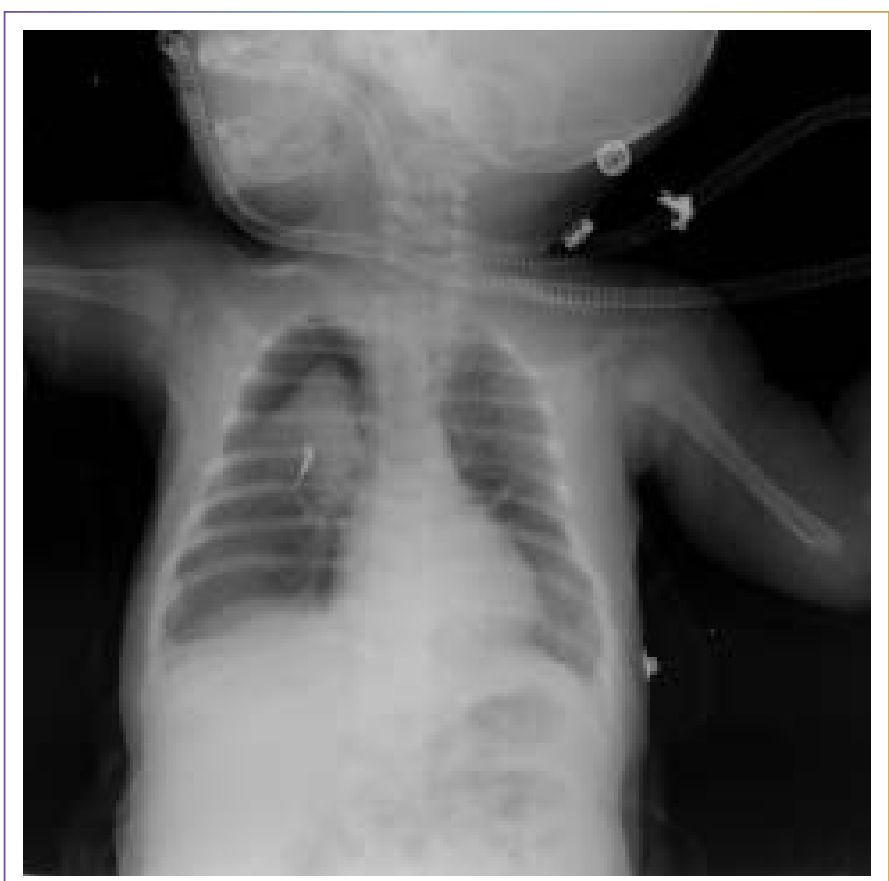

Şekil 2. Sağ akciğerde pnömotoraks.

Ekokardiyografik incelemesinde patoloji saptanmamıştır. Kentöz öksürüğü olması nedeniyle nazofarengeal sürüntü örneği alınmıştır. Bordetella pertussis negatif saptanmıştır. Solunum yolu infeksiyonu panelinde respiratuvar sinsityal virüs (RSV) A/B ve Streptococcus pneumoniae pozitif tespit edilmiştir.

Yatışının beşinci gününde takipne ve dispnesi belirginleşen hastanın kontrol akciğer grafisi çekilmiş, sağ akciğerde pnömotoraks oluştuğu görülmüştür (Şekil 2).

Hasta çocuk yoğun bakım ünitesine transfer edilmiştir. Toraks kateteri takılarak sualtı drenajı uygulanmıştır. Kontrol grafisinde akciğerin ekspanse olduğu görülmüştür. Ayırıcı tanı açısından kontrastlı toraks bilgisiyarlı tomografi (BT) incelemesinde; sağ akciğer üst lob posteriorda konsolide kollabe görünüm, sol akciğer alt lob posterobazal ve lateral bazalde subsegmental atelektaziler ve plevral kalınlaşmalar, tüm mediastinal boşluklarda yaygın septalı hava kisti görünümünde pnömomediastinum izlenmiştir. Ayrıca karina altı sağ ana bronş seviyesinde özefagus sağ lateral duvarda 1,4 mm çaplı şüpheli defekt? ile uyumlu olabilecek görünüm ve komşuluğunda posterior mediastende loküle olmuş serbest hava saptanmıştır (özefagus rüptürü?), alt boyun kesitlerinde ve göğüs ön/arka duvarında yaygın cilt altı yumuşak doku amfizemi gözlenmiştir (Şekil 3).

Hasta pediatrik cerrahi kliniği ile konsülte edilmiş, peroral metilen mavisi verilmiş, ancak göğüs tüpüne geçişin olmadığı görülmüştür. Üst gastrointestinal endoskopik inceleme yapılmış, patoloji saptanmamıştır.

İzleminde solunum sıkıntısı azalan hasta peroral beslenmiştir. Yatışının 10. gününde kontrol toraks BT çekilmiş; pnömotoraksın regrese olduğu görülmüş, toraks tüpü çekilmiştir. Kliniği stabil seyreden hasta pediatri servisine devredilmiştir.

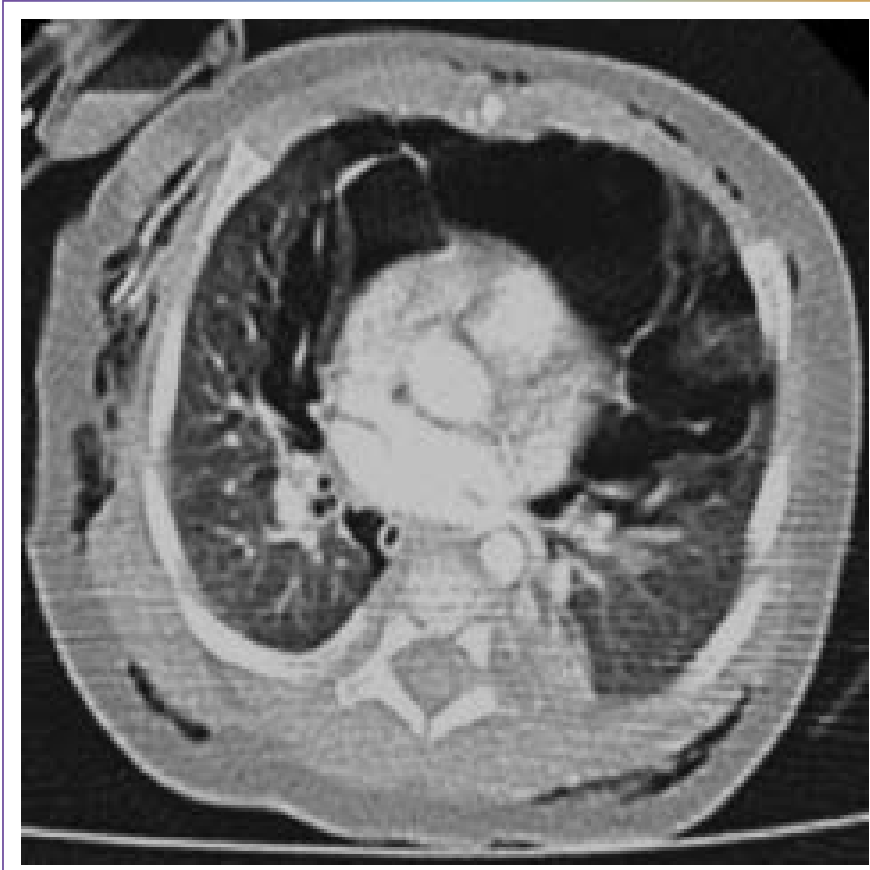

Şekil 3. Tüm mediastinal boşluklarda yaygın septalı hava kisti görünümünde pnömomediastinum göğüs ön/arka duvarında yaygın cilt alt yumuşak doku amfizemi.

\section{TARTIŞMA}

YANKO tedavisinin etkinliği ve belirgin yan etkilerinin olmaması, bu tedavi şeklinin yoğun bakım ünitelerinin yanı sıra servis ve acillerde de yaygın olarak kullanılmasının yolunu açmıştır $(4,5)$. Pnömotoraks, nazal mukoza ülserasyonu ve burun kanaması, batın distansiyonu, bradikardi, bradipne uygulama sırasında gözlenebilen yan etkilerdendir.

Çocuk acilde tedavi uygulanan bir olgu serisinde $(n=71)$ sadece bir astımlı olguda pnömotoraks gözlenmiştir (6). Başlıca tanının bronşiyolit olduğu karma olgu serilerinde YANKO tedavisi ile hiçbir yan etkinin görülmediği bildirilmiştir (7). YANKO tedavisinin bronşiyolitli çocuklarda kullanımı ile ilgili yapılan bir pilot çalışmada, 61 çocuk hastanın hiçbirinde istenmeyen duruma rastlanmadığı belirtilmiştir (8). Bronşiyolit endikasyonuyla YANKO tedavisi uygulanan hastalarda yapılan diğer bir çalışmada da 12 ay ve altındaki 58 bebekten birinde entübasyon ve mekanik ventilasyon desteği ile düzelen pnömotoraks bildirilmiştir (9).

Oto ve arkadaşları yaptıkları çalışmada, çocuk yoğun bakım ünitesinde akut hipoksemik solunum yetmezliği nedeniyle YANKO tedavisi uyguladıkları 50 hastanın hiçbirinde hava kaçağı sendromuna rastlamadıklarını bildirmişlerdir (10).

Ağır akut bronşiyolitin tedavisi sırasında; hastane ya da çocuk yoğun bakım ortamı, anneden ayrılma anksiyetesi, YANKO ve diğer noninvaziv mekanik ventilasyon uygulamaları çocukları ajite etmekte, ağlama ve huzursuzluğa bağlı olarak hava yolu direnci daha da artmaktadır. Bu durum hem mevcut solunum sıkıntısını arttirabilmekte hem de YANKO ve diğer noninvaziv solunum destek tedavilerine hasta uyumunu 
azaltarak cihaz-hasta uyumsuzluğu ve pnömotoraks gibi istenmeyen durumlara yol açabilmektedir (11). Bu nedenle bu hastalarda noninvaziv solunum desteği alsın ya da almasın beta2 reseptörleri uyararak bronkodilatasyona neden olan, iki ay üstü çocuklarda kullanımı güvenli ve analjezik-sedatif etkileri olan ketaminin infüzyon şeklinde verilmesinin faydalı olduğu, akciğer kompliyansını arttırıp pnömotoraks ve akciğer hasarı gibi istenmeyen yan etkileri engelleyebileceği belirtilmektedir (12). Benzer şekilde Hedge ve arkadaşları da çalışmalarında YANKO uygulaması sırasında pnömotoraks ve pnömomediastinum gelişen üç olgu bildirmişlerdir (13). Bu komplikasyonlara uygunsuz nazal kanül kullanımı ve yeterli sedasyon/hasta uyumunun oluşturulamaması sebep olarak gösterilmektedir. Burada anlatılan olgu ajite değildi ve cihaz-hasta uyumsuzluğu yaşanmadı, bu nedenle sedasyon infüzyon ihtiyacı olmadı.

YANKO tedavisi etkin ve güvenilir bir yöntemdir, ancak nadir bir komplikasyon olmakla birlikte pnömotoraksın gelişebileceği hatırlanmalı ve hasta yakın takip edilmelidir.

Hasta Onamı: Yazılı hasta onamı bu çalışmaya katılan hastanın ailesinden alınmıştır.

Çıkar Çatışması: Yazarlar çıkar çatışması bildirmemişlerdir.

Mali Destek: Yazarlar bu çalışma için mali destek almadıklarını beyan etmişlerdir.

Yazarlık Katkıları: Fikir - SE, GA; Tasarım - SE, Hi; Denetmele - SE, Ci; Kaynaklar-Ci, GA; Malzemeler - SE; Data collection and/or processing - GA, Hi; Analiz ve/veya Yorum - SE, GA; Literatür Taraması - SE, Hi; Yazıyı Yazan - SE; Eleştirel İnceleme - GA.

Informed Consent: Written informed consent was obtained from the family of the patient who participated in this study.

Conflict of Interest: No conflict of interest was declared by the authors.

Financial Disclosure: The authors declared that this study has received no financial support.

Authorship Contributions: Concept - SE, GA; Design - SE, Hi; Supervision-SE, Ci; Fundings - Ci, GA; Materials - SE; Veri Toplanması ve/veya İşlemesi - GA, Hi; Analysis and/or interpretation - SE, GA; Literature review - SE, HI; Writing - SE; Critical review - GA.

\section{KAYNAKLAR}

1. Pham TM, O'Malley L, Mayfield S, Martin S, Schibler A. The effect of high flow nasal cannula therapy on the work of breathing in infants with bronchiolitis. Pediatr Pulmonol 2014;50:713-20.

2. Baudin F, Gagnon S, Crulli B, Proulx F, Jouvet P, Emeriaud G. Modalities and complications associated with the use of high-flow nasal cannula: experience in a pediatric ICU. Respir Care 2016;61:1305-10.

3. McKiernan C, Chua LC, Visintainer PF, Allen H. High flow nasal cannulae therapy in infants with bronchiolitis. J Pediatr 2010;156:634-8.

4. Mikalsen IB, Davis P, Oymar K. High flow nasal cannula in children: a literature review. Scand J Trauma Resusc Emerg Med 2016;24:93.

5. Long E, Babl FE, Duke T. Is there a role for humidified heated highflow nasal cannula therapy in paediatric emergency departments. Emerg Med J 2016;33:386-9.

6. Bressan S, Balzani M, Krauss B, Pettenazzo A, Zanconato S, Baraldi E. High flow nasal cannula oxygen for bronchiolitis in a pediatric ward: a pilot study. Eur J Pediatr 2013;172:1649-56.

7. Milani GP, Plebani AM, Arturi E, Brusa D, Esposito S, Dell'Era L, et al. Using a high-flow nasal cannula provided superior results to low-flow oxygen delivery in moderate to severe bronchiolitis. Acta Paediatr 2016;105:e368-72.

8. Mayfield S, Jauncey-Cooke J, Hough JL, Schibler A, Gibbons K, Bogossian F. High-flow nasal cannula therapy for respiratory support in children. Cochrane Database Syst Rev 2014;3:CD009850. 22.10.10.

9. Dani C, Pratesi S, Migliori C, Bertini G. High flow nasal cannula therapy as respiratory support in the preterm infant. Pediatr Pulmonol 2009;44:629-34.

10. Oto A, Erdoğan S, Boşnak M. Oxygen therapy via high flow nasal cannula in pediatric intensive care unit. Turk J Pediatr 2016;58:37782.

11. Golding CL, Miller JL, Gessouroun MR, Johnson PN. Ketamine continuous infusions in critically ill infants and children. Ann Pharmacother 2016;50:234-41.

12. Kshirsagar V, Ahmed V, Colaco S. Use of ketamine in refractory bronchospasm: a study of 20 cases. JKIMSU 2013;2:60-8.

13. Hegde S, Prodhan P. Serious air leak syndrome complicating high-flow nasal cannula therapy: a report of 3 cases. Pediatrics 2013;131:939-44. 